\title{
WEEE data management in Germany and Serbia
}

\author{
Diedler S. ${ }^{1,}{ }^{*}$, Hobohm J. ${ }^{1}$, Batinic B. ${ }^{2}$, Kalverkamp M. ${ }^{3}$ and Kuchta K. ${ }^{1}$ \\ ${ }^{1}$ TUHH, Hamburg University of Technology, IUE; Harburger Schlossstr.36, 21079 Hamburg, Germany \\ ${ }^{2}$ University of Novi Sad, Faculty of Technical Sciences, Department of Environmental Engineering and Occupational Safety and Health, \\ Trg Dositeja Obradovica 6, 21000 Novi Sad, Serbia \\ ${ }^{3}$ Cascade Use, Carl von Ossietzky University of Oldenburg, Ammerländer Heerstraße 114-118, 26129 Oldenburg, Germany \\ Received: 28/02/2018, Accepted: 10/05/2018, Available online: 26/09/2018 \\ *to whom all correspondence should be addressed: e-mail: sascha.diedler@tuhh.de \\ https://doi.org/10.30955/gnj.002657
}

\section{Abstract}

The generation and processing of waste electrical and electronic equipment (WEEE) has given rise to numerous challenges and accordingly preventive approaches, due to governmental and environmental regulatory pressure. Yet, main requirements and practices are standard between different countries. This paper investigates the facilities of WEEE processing using a German case study, as grounded in EU legislature. This case study was compared to another case study in Serbia, with different processing steps and requirements. The facilities available in both countries were assessed to report contrasts between the two. Furthermore, the data requirements and standardisation approaches are briefly outlined as part of recommendations for implementation in WEEE facilities for processes, standardisation and optimisation based on identified gaps in Serbia WEEE data management.

Keywords: Urban mining, metal recovery, collection, sustainability, e-waste, pre-treatment, extended producer responsibility.

\section{Introduction}

WEEE recycling has a critical focus in modern sustainability, due to the increasing pressure on scarce resources, such as increased consumption of critical metals in electronics, together with the increased volume of scrap entering waste streams and landfills. Given the material composition of WEEE, landfilling is extremely hazardous attributable to the limited bio-degradability of polymers, the massive amounts of metal losses and the toxicity of batteries and storage units. The European Union (EU) has placed a very strong emphasis on the effective processing of WEEE by e.g. the extended producer responsibility with Directives such as 2012/19/EU and RoHS 2002/95/EC. However, numerous challenges have arisen with its implementation, such as procurement and collection of separated versus non-separated waste, categorisation of WEEE, effective sorting procedures, information management and sharing, together with numerous interrelated challenges.
WEEE collection and processing facilities require strong support from governments and new innovations to effectively address these identified challenges. Outside of the EU, similar challenges have been experienced, which poses the question of whether common challenges can result in feasible collection and processing strategies in facilities between EU and non-EU countries. In this study, Germany and Serbia were selected as representatives for each scenario, respectively. Germany has been chosen as an example for good practice for WEEE data management within the EU, Serbia as an EU candidate striving for adopting all WEEE Directive 2012/19/EU requirements. Examples of key findings from various international collection systems provide an indication to the differing goals and challenges of various European countries, as determined by various researchers (Table 1 ).

\section{Methodology}

Within this work, the capabilities of identifying WEEE facilities and the management of related data in Germany (EU country) and Serbia (non-EU country) are analysed via literature research. Based on a case study investigated in Germany as benchmark, recommendations and extensions to improve the system in Serbia are derived. Therefore, the availability of data regarding WEEE is disclosed for both countries. Major gaps and possible steps to improve the overall WEEE data management in Serbia are outlined and discussed.

\subsection{Availability of data regarding WEEE in Germany}

According to the WEEE Directive 2012/19, EU member states are encouraged to collect relevant data about WEEE, such as amounts and terms of treatment. In Germany, the treatment of WEEE is regulated by the ElektroG2, which has been stipulated since 2015 as update of the ElektroG that was enforced in 2005. With the ElektroG, the "national register for waste electric equipment" (EAR) has been implemented into German law to coordinate all WEEE treatment actions and to ensure fulfilling collection targets, in addition to defining producer responsibilities. EAR serves as a central regulatory body for implementation and maintenance of 
the Electrical and Electronic Equipment (EEE) Act and thus serves as the coordination centre for all WEEE flows in Germany.

Table 1. Literature sources with focus on WEEE collection systems

\begin{tabular}{|c|c|c|}
\hline Source & Key Findings & $\begin{array}{l}\text { Country/ } \\
\text { Region }\end{array}$ \\
\hline $\begin{array}{c}\text { (Gomes et al., } \\
\text { 2011) }\end{array}$ & $\begin{array}{l}\text { Collection system must } \\
\text { be adapted to the } \\
\text { logistic processes for } \\
\text { economical recycling to } \\
\text { be sustainably feasible }\end{array}$ & Portugal \\
\hline $\begin{array}{c}\text { (Gamberini et al., } \\
\text { 2009) }\end{array}$ & $\begin{array}{c}\text { Collection containers } \\
\text { should be decentralised, } \\
\text { such as at stores }\end{array}$ & Italy \\
\hline $\begin{array}{l}\text { (Barba-Gutiérrez } \\
\text { et al., 2008) }\end{array}$ & $\begin{array}{l}\text { Ecological direction of } \\
\text { recycling is determined } \\
\text { by logistics }\end{array}$ & Spain \\
\hline $\begin{array}{c}\text { (Nowakowski, } \\
\text { 2016) } \\
\end{array}$ & $\begin{array}{c}\text { Adaption of collection } \\
\text { vehicles }\end{array}$ & Poland \\
\hline $\begin{array}{l}\text { (Grunow und } \\
\text { Gobbi, 2009) }\end{array}$ & $\begin{array}{c}\text { Strategic planning } \\
\text { Strategic planning of the } \\
\text { collection system and } \\
\text { framework }\end{array}$ & Denmark \\
\hline $\begin{array}{c}\text { (Gamberini et al., } \\
\text { 2010) }\end{array}$ & Decision support tool & Italy \\
\hline (Cao et al., 2016) & $\begin{array}{l}\text { Skills development and } \\
\text { training of staff }\end{array}$ & China \\
\hline $\begin{array}{l}\text { (Salhofer und } \\
\text { Tesar, 2011) }\end{array}$ & \multirow{2}{*}{$\begin{array}{l}\text { Strengthening the } \\
\text { development framework } \\
\text { of the collection system }\end{array}$} & \multirow{2}{*}{ Austria } \\
\hline $\begin{array}{c}\text { (Tanskanen und } \\
\text { Butler, 2007) }\end{array}$ & & \\
\hline (Salhofer, 2014) & $\begin{array}{c}\text { Development of the } \\
\text { collection system with } \\
\text { focus placed on smaller } \\
\text { items }\end{array}$ & Europa \\
\hline $\begin{array}{c}\text { (Friege et al., } \\
\text { 2015) }\end{array}$ & $\begin{array}{l}\text { Transparency and } \\
\text { application of the } \\
\text { collection system }\end{array}$ & $\begin{array}{l}\text { Sweden, } \\
\text { Denmark, } \\
\text { Switzerland, } \\
\text { Germany, } \\
\text { Belgium }\end{array}$ \\
\hline
\end{tabular}

As German coordination centre regarding WEEE, EAR requires all WEEE collection points, recycling yards, providers of (pre-)treatment facilities and related producers to register at their platform. Due to its online platform (https://www.stiftung-ear.de/verzeichnisse/), EAR provides all collected information incl. locations of related facilities transparently and readily accessible. Currently the platform provides information about 11904 collection points, 26317 manufactures respectively authorised representatives and 399 pre-treatment facilities. As well the number of producer registrations at the EAR rose from about 4000 since its founding in 2005 to about 15000 in 2017, following the webpage of the EAR.

Since 2015, the ElektroG2 is in force as the German national law regarding various WEEE aspects. Due to ElektroG2, collection targets according to Directive 2012/19/EU have been established and the producer's responsibilities regarding e.g. product design and development are implied. To support consumers in disposing WEEE into dedicated collection points, ElektroG2 provides labels on EEE with instructions about proper usage and disposal of end-of-life items. Since July 2016, thanks to ElektroG2, it is also mandatory for distributors and online resellers to take back WEEE from consumers.

Within ElektroG2 data from registered producers, collection points and treatment facilities are collected. To ensure suitable numbers of containers for each WEEE category at public collection points, producers, distributors and resellers are registered at the Clearing House (Stiftung EAR). Here the different parties inform about the annually amounts of EEE put on the market in comparison to the WEEE collected, which supports coordinating the collection from producers. Further responsibilities in terms of assuring proper operations are assumed by public waste management authorities. It is designated that producers cover all additional costs if improper collection or treatment occurs. Figure 1 represents the collaboration of producers and the EAR regarding the provision of reliable data regarding WEEE management in Germany.

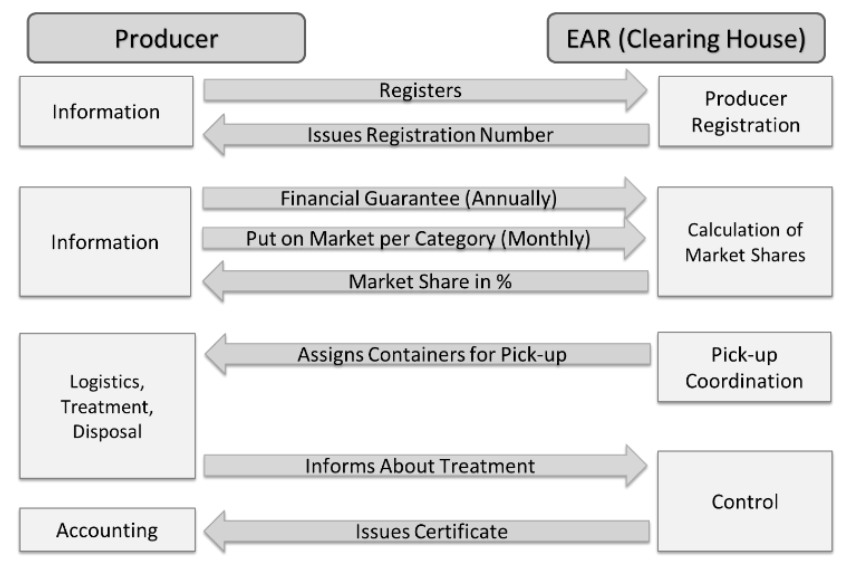

Figure 1. collaboration of producer and EAR to provide data regarding WEEE (Deubzer, 2011, modified)

The producer specifies to the EAR the type of EEE they put on market by providing basic information about their business. The producers further provide to the EAR information about their volatility (annually) and the amount of EEE per category they put on market each month. As every producer must provide these kind of information, EAR calculates their market share and make the information available. Due to the knowledge about the overall amounts of EEE on market, EAR can arrange the pick-up coordination of WEEE by assigning adequate numbers of containers at relevant locations. As EAR is assigned by law to manage all data regarding WEEE in Germany and due to the producer's responsibility, all information regarding logistics, treatment and disposal are provided by the producer to the EAR.

An additional challenge to the procurement and tracking of WEEE are storage channels and outbound logistics. The sustainability of the processes is constrained by staff 
factors where staff should be made accountable (Nowakowski, 2016). Gambrini et al. (2010) developed an optimisation of collection systems through a decision tool based on key performance indicators of staff time versus collection and vehicle use. The decision tool was applied in Northern Italy with success found in adaption and implementation. Gomes et al. (2011) indicated that a strategically applied and structured network between collection and recycling in Portugal showed relevant decision factors for collection facilities where costs could be minimised. The strategic network coupled with the tool has many benefits, such as increased transparency and reduces the administrative overheads of such facilities through automation. Additionally, the market entry of new facilities is supported through various entry opportunities with the standardised collection system (Grunow und Gobbi, 2009). Due to the legislative pressure of producers and resellers to collect waste properly, the collection points should be as publicly adoptable as possible to maximise the collection rates (Gamberini et al., 2009) while addressing social issues such as hoarding of smaller devices for potential later use that is never realised. The final consideration refers to the public visibility of systems (Cao et al., 2016; Yla-Mella et al., 2015). With these considerations, decentralised collection systems are not primary processing points, but could assist in combining waste streams with reasonable pre-treatment (Salhofer, 2014).

\subsection{Availability of data regarding WEEE in Serbia}

The Republic of Serbia (RS) is an EU candidate country that, through national legislation, harmonised and adopted the majority of the WEEE Directive 2012/19 requirements with certain targets postponed in relation to the legislation currently valid for EU member states. For example, $4.0 \mathrm{~kg} / \mathrm{cap}$ target of collected WEEE needs to be achieved before the end of 2019. This contrasts with EU countries collection target, which starting from 2016, was set to the $45 \%$ of EEE placed on the market in the previous three years.

WEEE collection schemes are still undeveloped. Although disposal of WEEE without prior treatment is not allowed, the majority of WEEE (especially from households), still gets mixed with municipal waste at landfills.

The current collection system is based on producer responsibility principles, where producers and importers of EEE are required to pay a certain fee (depending on the EEE type), which aims at establishing appropriate management of WEEE. Recycling and other companies are then subsidised through the Ministry of Environmental Protection (MEP) with 108 to $900 €$ per tonne of treated WEEE (Official Gazette of the RS, No 81/14). Thus, companies that perform treatment and recycling play the role of WEEE collectors also.
In terms of WEEE tracking system, recording and reporting procedure is defined within Law on Waste Management (Official Gazette of the RS, No 36/09, 88/10 and 14/16) and by-laws. All WEEE related information is collected and processed through the National Registry of Pollution Sources (NRPS) information system, established by the Serbian Environmental Protection Agency (SEPA). Figure 2 illustrates the general system of the WEEE related information flow in Serbia.

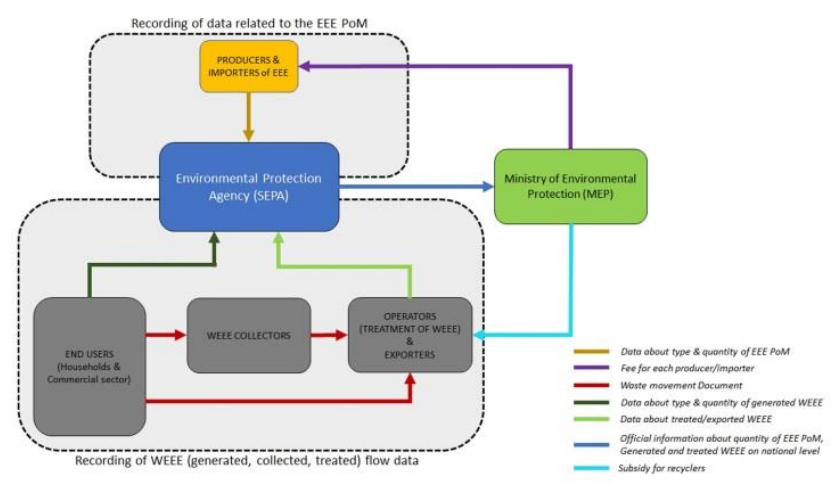

Figure 2. WEEE related data flow system in Serbia

In line with the "Regulation on products that become specific waste streams after use, on the daily log form for records of the quantity and type of products produced and imported" (Official Gazette of the RS, No 54/10), producers and importers of EEE are obliged to keep daily records of all EEE that are produced or imported. In the form of annual reports, information about the total number, the mass and the type of EEE placed on the market are transmitted through the online NRPS platform to the SEPA. Based on the received information (i.e. quantity and category of EEE placed on the market), a certain fee for each producer/importer is calculated (as a part of EPR system obligation).

WEEE generated from the end users (households and commercial sector) should be separated by source from the other waste streams (e.g. municipal solid waste) and received by the companies in charge for the collection of WEEE, or directly delivered to the pre-treatment facilities. Companies involved in collection or treatment of WEEE are required to have permits issued by the MEP. A completed Waste Movement Document (Official Gazette of the RS, No 114/13) should record all transported WEEE. This document contains information about the type of WEEE (index number from waste catalogue), mass, type of packaging, etc. The waste index number of the waste movement document is important for the appropriate tracking and further treatment of the collected material. Like the EEE producers/importers, all generators and operators of WEEE must record all annual quantities of treated/exported WEEE. Related information is consequently sent to the SEPA. Required data, that should be recorded are defined in the rulebook (Official Gazette of the RS, No 95/10) for the WEEE generators, which include information such as: the waste 
index number, the generated WEEE, further delivered and temporary stored quantities, the number of the waste movement document with the name and the permit number of the company that took over the waste. On the other side, pre-treatment facilities besides description and amount of received WEEE are obliged to send additional information such as general description of applied treatment process, but also information related to the export of some output materials from the process (e.g. hazardous components), if exists.

Table 2. Main identified gaps in Serbia WEEE data management and required action to achieve "good practice" status

\begin{tabular}{|c|c|c|c|}
\hline Gaps classıfıcatıon & & Descriptıon of ıdentıfıed gaps & Recommendatıon for improvements \\
\hline \multirow{8}{*}{ Technical \& infrastructural } & $>$ & $\begin{array}{l}\text { WEEE collection schemes are } \\
\text { still undeveloped. }\end{array}$ & $\begin{array}{l}\checkmark \text { Define clear national and local investment strategies } \\
\text { for the establishment of collection points in various } \\
\text { urban hotspots at municipality level. }\end{array}$ \\
\hline & $>$ & $\begin{array}{l}\text { Number of collection points, } \\
\text { recycling yards and facilities for } \\
\text { WEEE treatment are inadequate. }\end{array}$ & $\begin{array}{l}\checkmark \text { In short timeframe priority should be to ensure } \\
\text { suitable numbers of containers for different WEEE } \\
\text { categories at commercial hotpots (e.g., }\end{array}$ \\
\hline & & & supermarkets, public buildings, etc.). \\
\hline & $>$ & $\begin{array}{l}\text { Consumers do not dispose WEEE } \\
\text { into dedicated collection points. }\end{array}$ & $\begin{array}{l}\checkmark \text { Motivation schemes for citizens and utility WEEE } \\
\text { collection companies (rewards and/or penalties }\end{array}$ \\
\hline & & & policy) should be clearly defined. \\
\hline & $>$ & $\begin{array}{l}\text { Majority of WEEE is still disposed } \\
\text { with municipal waste at landfills. }\end{array}$ & $\begin{array}{l}\checkmark \quad \text { Instructions about proper usage and disposal of end- } \\
\text { of-life EEE need to be readily available. }\end{array}$ \\
\hline & $>$ & $\begin{array}{l}\text { Retailers are not keen to receive } \\
\text { WEEE from consumers. }\end{array}$ & $\begin{array}{l}\checkmark \quad \text { Take back system for distributors and online resellers } \\
\text { should be mandatory and regulatory defined. }\end{array}$ \\
\hline & $>$ & $\begin{array}{l}\text { Pre-treatment facilities in Serbia } \\
\text { face a challenge regarding } \\
\text { profitability and capacities for } \\
\text { treatment of hazardous } \\
\text { components from WEEE. }\end{array}$ & $\begin{array}{l}\checkmark \text { WEEE recyclers should be subsidized for treatment of } \\
\text { hazardous components and other recovered } \\
\text { materials from WEEE and encouraged to introduce } \\
\text { more advanced treatment processes. }\end{array}$ \\
\hline \multirow[t]{2}{*}{$\begin{array}{l}\text { Legal \& } \\
\text { institutional/regulatory } \\
\text { framework }\end{array}$} & $>$ & $\begin{array}{l}\text { Lack of coordinating body } \\
\text { responsible to ensure fulfilling of } \\
\text { targets stipulated in legislative and } \\
\text { fully implement producer } \\
\text { responsibility principles. }\end{array}$ & $\begin{array}{l}\checkmark \text { Apart from SEPA and the MAEP, introduction of a } \\
\text { 'national operator' as a central regulatory body that } \\
\text { would coordinate activities related to the } \\
\text { establishment of producer responsibility principles } \\
\text { and the achievement of WEEE Directive 2012/19 } \\
\text { requirements is crucial. }\end{array}$ \\
\hline & $>$ & $\begin{array}{l}\text { Significant number of producers } \\
\text { and importers of EEE do not follow } \\
\text { obligations to record EEE placed } \\
\text { on the market and/or do not refer } \\
\text { all the quantities properly, making } \\
\text { monitoring and planning more }\end{array}$ & $\begin{array}{l}\text { Effective mechanisms of control enforcement should } \\
\text { be applied for producers and importers of EEE in } \\
\text { terms of their responsibilities and submission of } \\
\text { consistent official data (e.g. introduction of more } \\
\text { strictly penalties policy and control of data } \\
\text { reliability). }\end{array}$ \\
\hline
\end{tabular}
challengeable.

$>$ Although a system of WEEE data tracking in Serbia is established, it is too general since same is used also for tracking of data for other special waste streams (e.g. waste tires, waste oils, end of life

Data management \& reporting vehicles, etc.).

$>$ Information obtained from the collection companies are too general, not comprehensive and often inconsistent.

$>$ Lack of reliable data related to the recycling/treatment of WEEE (e.g. type of pre-treatment process, quantity \& quality of output materials, etc.).

$>$ Characteristics of related WEEE facilities are not transparent and only partially accessible to the public. $\checkmark \quad$ More comprehensive and specially designed data tracking system related solely to the WEEE should be introduced, covering detail information about WEEE flows during all stages (i.e. from collection to final treatment phase). $\checkmark \quad$ Recommendation is to develop open access national online platform where all WEEE related data can be transparently visible to the public (i.e. information about all WEEE collection points, recycling yards, (pre-) treatment facilities, etc.). 
Although a system of WEEE tracking in Serbia is established in general, there are still many issues that are apparent in practice. To avoid paying the fee for WEEE management, many producers and importers of EEE still do not follow obligations to record EEE which were put on market, or do not refer all the quantities properly. This is obvious if latest official data (SEPA, 2017) are considered, where only 9578 tonnes of EEE were placed on the Serbian market in 2016, corresponding to merely $1.33 \mathrm{~kg}$ of EEE per capita, which is significantly lower than the anticipated actual rate.

In addition, precise data on quantities of generated WEEE at a national level still do not exist, mainly because the majority of WEEE generated from households ends up mixed with municipal waste and thus is not possible to be tracked and recorded. However, estimated amounts are approximately 80000 tonnes per year, which corresponds to the $11.1 \mathrm{~kg} / \mathrm{cap} /$ year (Marinkovic et al., 2017).

Information obtained from the recycling companies is not comprehensive and too general. One of the reasons is that, information required by the Rulebook (Official Gazette of the RS, No 95/10) are not designed and adapted solely to the needs of the treatment of WEEE, but also for tracking of data for recycling of other special waste streams (e.g. waste tires, waste oils, end of life vehicles, etc.). Thus, some of the important information related to the recycling/treatment of WEEE is not recorded. There is a lack of data related to the type of pre-treatment process, quantity and quality of output materials in relation to the certain WEEE category, and the source of exported or material sent further to the final treatment stage. All related information is only partially accessible to the public. According to data obtained from leading recycling companies, about $15000-20000$ tons of WEEE are treated annually, which also represents the total amount of collected WEEE. Based on these figures, it can be estimated that about $2.78 \mathrm{~kg}$ per inhabitant of WEEE is annually collected in Serbia (see Table 3).

Because of the mentioned circumstances, the data reliability is impaired already at the initial data collation point (i.e. at import or sales of EEE). Similarly, the data collected on WEEE at collection and thereafter at the point of treatment is inconsistent and adds to the uncertainty of available data. Therefore, the data reliability is a crucial issue for Serbian aspirations to adopt all WEEE Directive 2012/19/EU requirements.

\section{Results and discussion}

WEEE related legislation in the EU is strongly centralised around national bodies based on the WEEE Directive 2012/19/EU, such as the ElektroG in Germany. This contrasts with Serbia, where no central regulatory body exists that serves as a national register for WEEE, to coordinate actions to achieve collection targets and fully implement producer responsibility principles. The EAR demonstrates good practices of how a detailed register of imported/sold EEE and collected WEEE produces benefits for the stakeholders involved, such as logistics providers or recycling facilities. Regulatory bodies enforced and supported by legislation exist at EU and German national level, particularly through the ministry of environmental affairs. Their parallel institutions in Serbia are SEPA and the MAEP. These institutions are crucial for the appropriate implementation of data collection, monitoring, validation, and controlling. However, limits exist to such institutions, for example, when the data collection and processing itself is not reliable or when the enforcement mechanisms lack appropriate means to counter potential data manipulation. The case of Serbia indicated that the data collected is unreliable in many cases. Therefore, planning and decision making based on such data is more prone to miss the intended outcomes.

In Serbia, collection schemes are undeveloped in comparison to the initiatives in Germany. This underdevelopment is strongly related to the number of collection points, recycling yards and facilities for WEEE treatment. In general, the uncertainty of the Serbian data prevents a more precise analysis of the situation. For example, although the share of WEEE collected compared to the WEEE generated (per capita) differs by only 10 percentage points, the estimated $2.78 \mathrm{~kg} / \mathrm{cap}$ WEEE collection already represent the positive scenario of $20000 \mathrm{t}$ of WEEE collected (see Table 3). In addition, if all WEEE collected in Serbia would be pre-treated in Serbia, the existing treatment facilities would have to process on average approx. three times as much WEEE than their German counterparts. In contrast to Serbia, Germany has a clear national investment strategy for the proper treatment of WEEE due to the development of recycling facilities and collection points in various urban hotspots and at a city level. Relevant locations are transparently visible due to the open access online platform of the EAR. Main identified gaps in Serbia WEEE data management are summarized in Table 2.

To catch up with EU member states, Serbia should adjust and amend its WEEE system in terms of the legal framework and the logistics system on a short- mediumand long-term basis. On a short-term basis, Serbia should focus on the improvement of the existing WEEE collection system, i.e. establish a strategic network of collection points at municipality level; this may include but is not limited to collection points at commercial hotpots (e.g. malls, supermarkets, electronic retailers) and at public buildings. At a medium-term, the legislative system should be adopted potentially including clearly defined motivation schemes for citizens and utility WEEE collection companies (e.g. defining appropriate rewards and/or penalties policy). With the current level of WEEE processing and the current prices of raw materials on the global market, pre-treatment facilities in Serbia face a challenge regarding profitability. Thus, WEEE recyclers should be additionally subsidised for treatment of 
hazardous components and other recovered materials from WEEE and encouraged to introduce more advanced treatment processes. However, prices for WEEE may change over time hence incentives schemes need to consider this. In this context, the implementation of deposit-based collection systems might be considered. Therefore, the implementation of such schemes requires some preparation hence is also a medium-term objective.

In the medium- to long-run, the introduction of a 'national operator' like EAR in Germany, that would oversee the coordination between relevant stakeholders, the implementation of activities related to the establishment of producer responsibility principles, and the achievement of WEEE Directive 2012/19 requirements, can significantly improve current WEEE management system in Serbia. Such operator could also be part of the short-term activities. However, the operator would be especially required to carry out tasks in the medium- to long-run perspective. Task comprise though are not limited to the coordination of stakeholders (medium-term) and the supervision and controlling of the collection system (long-term) in order to establish a continuous improvement approach that aims at the alignment of the Serbian collection system with state-of-the art European collection systems.

Data availability is of concern due to the limited collection of data and the unreliability of data. The case from Serbia showed that there is some data available at a national level regarding WEEE collection and treatment rates. But because producers and importers of EEE do not record and transmit all quantities of EEE, together with limited delivered data from pre-treatment companies, the data regarding pre-treatment, quantities and quality of output materials is questionable. Although this data is not reliable, it still allows the gauging and estimating of recycling rates in Serbia. Germany collects data through EAR and at a city-level, but this data is not easily accessible to the public as reporting is directed at an EU level rather than to the national public. A similar trend is visible in Serbia where WEEE management data is not considered to be complete and its availability is extremely limited. This limitation of data availability hinders better monitoring and assessment in Germany and may even obstruct further improvements in Serbia. Data collection on WEEE is a basic step required to improve the overall system in place. First, the data entails a form of control on producers resulting in an increase in their efforts to comply with their responsibilities. Second, the data may reveal the performance of the entire collection system, and of individual collection points. Furthermore, the collected data can be analysed with the objective to reveal insights on the consumer behaviour towards WEEE disposal. Results of data analyses on the mentioned aspects may serve to further improve the network of collection points, by developing managerial or policy means to increase the disposal of devices formerly hoarded. Table 3 visualises further basic data regarding WEEE capacities in Germany and Serbia.
Table 3. Data regarding WEEE capacities in Germany and Serbia for 2016

\begin{tabular}{|c|c|c|}
\hline & Germany & Serbia \\
\hline Population $^{1}$ & 82667685 & 7057412 \\
\hline $\begin{array}{l}\text { population density } \\
\qquad\left(/ \mathrm{km}^{2}\right)^{1}\end{array}$ & 237 & 81 \\
\hline $\begin{array}{l}\text { WEEE generated } \\
\text { (kg/cap/year) }\end{array}$ & $22.8^{3}$ & $11.10^{6}$ \\
\hline $\begin{array}{l}\text { No. of WEEE } \\
\text { collection points }\end{array}$ & $11904^{2}$ & unknown \\
\hline $\begin{array}{l}\text { No. of WEEE pre- } \\
\text { treatment facilities }\end{array}$ & $399^{2}$ & $4^{4}$ \\
\hline $\begin{array}{l}\text { total WEEE collected } \\
(\mathrm{t})\end{array}$ & $782214^{5}$ & $15000-20000^{4}$ \\
\hline collection (kg/cap) & $\begin{array}{c}8.62 \text { ( } \approx 36 \% \text { of } \\
\text { WEEE generated) }\end{array}$ & $\begin{array}{c}2.78^{4}(\approx 25 \% \text { of } \\
\text { WEEE generated) }\end{array}$ \\
\hline
\end{tabular}

${ }^{1}$ http://www.worldbank.org [accessed 2017]

${ }^{2}$ https://www.stiftung-ear.de/verzeichnisse/[accessed 2017]

${ }^{3}$ https://de.statista.com/ [accessed 2017]

${ }^{4}$ SEPA, 2017

${ }^{5}$ https://www.umweltbundesamt.de/daten/ressourcenabfall/verwertung-entsorgung-ausgewaeh/ter-

abfallarten/elektro-elektronikaltgeraete

${ }^{6}$ estimated

It can be noticed that the number of WEEE pre-treatment facilities is significantly higher in Germany than in Serbia. However, average treatment capacity per facility is higher in Serbia, which can be explained due to fact that companies for WEEE pre-treatment in Serbia can't actually treat $100 \%$ of the collected WEEE. In four main companies for WEEE pre-treatment processes are mainly concerned with manual dismantling of WEEE, with mechanical treatment for only certain WEEE types, such as refrigerators, CRT screens, fluorescent lamps, etc. Thus, the most of hazardous materials and components removed within the pre-treatment stage are further exported to the final treatment in some of the EU countries.

The population density between the two countries also plays a significant role in the sparsity of collection points and WEEE collection options. Germany has a higher population density with $237 / \mathrm{km}^{2}\left(81 / \mathrm{km}^{2}\right.$ in Serbia) (see Table 3) with higher EEE production and imports, which puts greater pressure on the country to adhere to the EU regulations. Nevertheless, complying with the WEEE regulation would support Serbia's aspirations as an EU candidate state from a different perspective.

\section{Conclusions}

The difference in the collection rates between Serbia and Germany can be attributed to several factors, such as legislative pressure and population density. Pressure from legislation clearly has a strong impact on WEEE collection and treatment in various countries and on setting and reaching targets. The collection rate has seen an increase over the last years, according to available open data. Evidence of legislative success indicates that this is an effective strategy but should also be incorporated as part of a larger composite strategy. Main steps to improve the overall WEEE management in Serbia are outlined within 
the gap analysis in Table 2. A commitment to increasing material recovery rates, especially critical metals, from WEEE together with reducing landfilled waste should be the key driver to improving WEEE collection and treatment both inside and outside of the EU.

Additionally, the availability of high quality data remains a concern for transparency and reporting adherence. The limited amount of data available to the public is an issue in recycling in general, but stronger so in WEEE. A prevalence for increasing agency reported, city reported, and nationally reported data is necessary for public awareness and trust. Increased communication and reporting standards also raise competitive pressure for other countries and open opportunities for collaboration through partner projects and innovation. This innovation could additionally address the apparent divide between the EU and non-EU countries, such as Serbia where EEE production, import and usage rates are high, nevertheless effective collection and treatment remains questionable, based on the available data.

A first step should be to improve the availability and especially the reliability of already existing data regarding WEEE management in Serbia. Based on reliable data on a city level, the collection system can be improved by understanding consumers' disposal behaviour. In addition to that, by comparing EEE put on market and collection amounts, losses of (W)EEE can be identified which can contribute to closing the loops of crucial resources.

\section{References}

Barba-Gutiérrez Y., Adenso-Diaz B. and Hopp M. (2008), An analysis of some environmental consequences of European electrical and electronic waste regulation, Resources, Conservation and Recycling, 52(3), 481-495.

Cao J., Chen Y., Shi B., Lu B., Zhang X., Ye X., Zhai G., Zhu C. and Zhou G. (2016), WEEE recycling in Zhejiang Province, China: generation, treatment, and public awareness, Journal of Cleaner Production, 127, 311-324.

Deubzer O. (2011), E-waste Management in Germany; report commissioned by GIZ, 2011, retrievable from http://www.weee-forum.org/documents/2011-e-waste-man agement-in-germany-report.

Directive E.C. (2012), Directive 2012/19/EU of the European Parliament and of the Council of 4 July 2012 on waste electrical and electronic equipment, WEEE, Official Journal of the European Union, 197, 38-71.

Directive R. (2003), Directive 2002/95/EC of the European Parliament and of the Council of 27 January 2003 on the restriction of the use of certain hazardous substances in electrical and electronic equipment. Official Journal of the European Union, 13, L37.

Friege H., Oberdörfer M. and Günther M. (2015), Optimising waste from electric and electronic equipment collection systems: A comparison of approaches in European countries, Waste Management \& Research, 33(3), 223-231.

Gamberini R., Gebennini E. and Rimini B. (2009), An innovative container for WEEE collection and transport: details and effects following the adoption, Waste Management, 29(11), 2846-2858.

Gamberini R., Gebennini E., Manzini R. and Ziveri A. (2010), On the integration of planning and environmental impact assessment for a WEEE transportation network - A case study, Resources, Conservation and Recycling, 54(11), 937-951.

Gomes I., Barbosa-Povoa A. and Novais A. (2011), Modeling a recovery network for WEEE: A case study in Portugal. Waste Management, 31, 1645-1660.

Grunow M. and Gobbi C. (2009), Designing the reverse network for WEEE in Denmark. CIRP Annals-Manufacturing Technology, 58(1), 391-394.

Law on Waste Management, Official Gazette of the Republic of Serbia, No 36/09, 88/10 and 14/16).

Marinkovic T., Batinic B. and Stanisavljevic N. (2017), Analysis of WEEE management in Republic of Serbia (in Serbian), Proceedings of Conference "Wastewaters, municipal waste and hazardous waste", Pirot, April 2017.

Nowakowski P. (2016), The influence of residents' behaviour on waste electrical and electronic equipment collection effectiveness, Waste Management \& Research, 31(11), 1126-1135.

Regulation of the amount and conditions for the allocation of incentives, Official Gazette of the Republic of Serbia, No $81 / 14$.

Regulation on products that become specific waste streams after use, on the daily log form for records of the quantity and type of products produced and imported, and on the annual report, on the method and time frame for submitting the annual report, on the fee payers, the calculation criteria, the amount and the method for the calculation and payment of the fee, Official Gazette of the Republic of Serbia, No 54/10, $86 / 11,15 / 12$ and $03 / 14$

Rulebook on the form of a daily record and annual waste Report with the filling in instructions, Official Gazette of the Republic of Serbia, No 95/10 and 88/15.

Rulebook on the form of hazardous waste movement document and filling in instructions, Official Gazette of the Republic of Serbia, No 114/13.

Salhofer S. and Tesar M. (2011), Assessment of removal of components containing hazardous substances from small WEEE in Austria. Journal of hazardous materials, 186(2), 1481-1488.

Salhofer S. (2014), Small, but powerful-why we should put more emphasis on the collection of small WEEE. In Proceedings SUM 2014, Second Symposium on Urban Mining, Bergamo, Italy.

SEPA - Serbian Environmental Protection Agency (2017), Report on special waste streams in Republic of Serbia in 2016 (in Serbian), Belgrade, 2017.

Tanskanen P. and Butler E. (2007), Mobile phone take back learning's from various initiatives. In Electronics \& the Environment, Proceedings of the 2007 IEEE International Symposium, 206-209.

Ylä-Mella J., Keiski R.L. and Pongrácz E. (2015), Electronic waste recovery in Finland: Consumers' perceptions towards recycling and re-use of mobile phones, Waste Management, 45, 374-384. 